Journal of Universal Language 5

March 2004, 47-83

\title{
Towards a Universal Typology of State of Affairs
}

\author{
Ana Ortigosa \\ University of La Rioja
}

\begin{abstract}
This paper addresses the issue of a lexical classification for predicates (usually referred to as 'Aktionsart') or more ideally for state of affairs (SoAs). In this sense, grounding my study on the Role and Reference Grammar (RRG) theoretical framework, I critically review the Aktionsart typology put forward by Van Valin \& LaPolla (1997) - henceforth VV\&LP, where I remark the inappropriateness of considering categories such as active accomplishments or the causatives. Throughout this paper, the compositionality of Aktionsart is also highlighted in the sense of regarding Aktionsart as a property of the whole clause (idealized situation types) rather than of just predicates. In this way, it is claimed that while it should be more adequate to establish a typology of SoAs, Aktionsart predicates may be also considered, as long as they are assigned a prototypical value. Finally, I present a possible typology for the most common SoAs found in English, while references are also made as regards the universality of such a classification.
\end{abstract}

Keywords: Aktionsart, aspect, compositionality, prototype 


\section{Introduction}

When talking about time and how it is expressed linguistically one should distinguish between two fundamental concepts: tense and aspect. In this sense, tense localizes a situation in time-before, around or after speech time. Aspect on the other hand, is concerned with the internal character of the situation as it is presented by the speaker. Therefore, aspect involves different ways of viewing the inner temporal constituency of a situation.

When dealing with aspectual marking, an important distinction should be made. Let us consider the following examples:

(1) a. Juana saw the movie yesterday.

b. My grandmother is knitting a new sweater.

c. The guy shot the cop.

d. She studied for two hours.

The first two sentences, in the perfective (1a) and imperfective aspect (1b), express the entireness and the ongoingness of a situation, respectively. However, although both (1c) and (1d) also appear in the perfective aspect, the internal temporal character of both SoAs is further specified by the inner temporal character of the predicates themselves: thus in (1c) shot refers to a punctual (non-durative) and telic (bounded) situation, while in (1d) study denotes a durative and non-telic situation. On this topic, it is worth considering Smith (1986). This author differentiates between what she denominates viewpoint aspect and situation type. In this sense, viewpoint aspect involves the forms and meanings associated with the perfective and imperfective perspectives. ${ }^{1}$ However, situation aspect deals with the

\footnotetext{
${ }^{1}$ It should be noted that many other authors like Dik (1997: 186) distinguish, apart from imperfective and perfective aspect, several others categories such as quantificational aspect (iterative, habitual, frequentative) or phasal aspect (progressive, ingressive, egressive, etc.).
} 
linguistic forms and meanings associated with idealized situation types. In other words, Smith (1986) distinguishes between the aspect denoted grammatically by the verbal form itself, and the aspect expressed by the kind of predicate (or more traditionally referred to as Aktionsart).

As regards situation aspect, Vendler's (1967) work constitutes one of the most significant studies on such a field. This author classified verbs depending on their inherent temporal properties and proposed four basic classes: states, activities, accomplishments and achievements. $^{2}$ The survey that will be carried out here on Aktionsart will be based on VV\&LP's (1997) study of the topic, which in turn rests on Vendler's work.

According to VV\&LP (1997: 93) the previous four Aktionsart classes can be described in terms of three main features: stativity, telicity and punctuality:

(2) a. State

b. Activity

c. Accomplishment

d. Achievement [+static], [-telic], [-punctual]

[-static], [-telic], [-punctual]

[-static], [+telic], [-punctual]

[-static], [+telic $],[+$ punctual $]$

The distinction between static and non-static predicates-or state-event distinction-is considered as the conceptual foundation of situation aspect. In this way, states are usually regarded as homogeneous, that is, they involve no change and hence cannot be seen as developing or ongoing; moreover, they are supposed to have indefinite temporal duration (although as it will be seen below, there are many stative situations which have a limited duration). Nevertheless, I will consider as the basic feature for distinguishing states from the

\footnotetext{
${ }^{2}$ Vendler's is not the only system of Aktionsart classification which has been proposed in the recent literature. See Dowty (1979), Talmy (1985), or Bache (1997), for instance.
} 
other kinds of SoAs their non-dynamic character, that is, stative situations do not imply any kind of 'force', 'energy' or interaction typically associated with dynamic happenings. In the case of nonstatic verbs, these predicates code an incident or something that is taking place. The feature of telicity has to do with whether nonstatic predicates have an inherent terminal point; that is, a predicate is [+telic] if it involves the reaching of an outcome. In this sense, states and activities are [-telic] or unbounded, that is to say, they do not need to attain any kind of goal, whereas accomplishments and achievements are [+telic] or bounded, hence they must conclude. Finally, the characteristic of punctuality involves the internal temporal duration of predicates. Thus, $[+$ punctual] predicates take place instantaneously-achievements-while [-punctual] predicates occur over a period of time—states, activities and accomplishments.

The examples in (3) illustrate the previous Aktionsart classes:

(3) a. State

b. Activity

c. Accomplishment

d. Achievement
The Spaniards are pleased with the Prince's engagement.

The kite is moving too fast.

The water froze in thirty minutes.

The building collapsed after the explosion.

VV\&LP (1997: 99) distinguish another class from the previous Aktionsart types, which they call 'active accomplishment'. This type of predicate refers to the accomplishment uses of activity verbs; thus, if an activity verb takes place together with a specific, referential or quantified object, the predicate becomes [+telic] since in this way, the reaching of a terminal point is involved in the action (e.g., John painted the house). However, if the object is indefinite (usually a mass noun or bare plural), the predicate should be considered as an activity; thus, an example like John painted houses represents an activity since houses is not a specific noun and consequently it does 
not delimitate the action, i.e., it does not provide a terminal point.

Finally, VV\&LP (1997: 97) make another distinction among the Aktionsart classes by differentiating spontaneous SoAs-like those in (3)-from induced SoAs. In this way, these authors remark that for each of the basic Aktionsart classes there is a corresponding causative class (also for active accomplishments). This can be seen in the following examples:

(4) a. Causative state:

The Prince's engagement pleases the Spaniards.

b. Causative activity:

The boy is moving the kite too fast.

c. Causative accomplishment:

The freezer froze the water in thirty minutes.

d. Causative achievement:

The explosion collapsed the building.

e. Causative active accomplishment:

My dad walked my sister to school.

Accordingly, the total number of Aktionsart classes considered by VV\&LP would consist of ten different types. ${ }^{3}$

Finally, VV\&LP (1997: 92) emphasize the necessity to differentiate between the basic Aktionsart interpretation of a verb, which would be found in its entry in the lexicon, from the Aktionsart interpretation it has in a specific clause. Thus, the influence of clausal elements such as adverbials, PPs, aspectual operators, etc. will often affect the Aktionsart construal of a predicate. This fact is usually referred to as the compositionality of Aktionsart.

3 Another crucial component of VV\&LP's Aktionsart system is a set of syntactic and semantic tests for determining the class membership of a verb in a particular sentence. Thus, these authors claim that only accomplishments and activities can occur with the progressive. For further information, see VV\&LP (1997: 94). 


\section{The Compositionality of Aktionsart}

The distinction between situation and viewpoint aspect has always been a topic full of controversy. That is, from a cognitive point of view, one could argue that grammatical aspect and Aktionsart are actually one and the same thing, the difference being a matter of individual lexicalization and grammaticalization processes. Nevertheless, it is methodologically problematic to define Aktionsart as a universal lexical category, since, as Sasse (1991: 38) remarks, there are some languages like Samoan-a Polynesian language-, which do not seem to have lexical Aktionsart.

In this way the idea of a classification of predicates in terms of their aspectual values is often abandoned since the Aktionsart interpretation for a verb will often, if not always, depend on the linguistic context in which it occurs. Thus, Bache (1997: 219) observes that although the type of action is very much a question of the lexical verb selected, we cannot talk about punctual, durative verbs, etc. since actionality can be changed without changing the verb. Bache (1997: 220) also points out that actional variation may result from variation in grammatical form, variation in intra or extra sentential context and/or variation in communicative function. Similarly, Dik (1997: 90) favours a typology of SoAs instead of a typology of predicates since many predicates can occur in predications which designate different types of SoAs. In these cases, the author remarks that the types of arguments and satellites, with which the predicate co-occurs, may establish the semantic nature of the whole predication.

As an outcome of arguments such as the previous ones, the notion of Aktionsart started to be addressed from a compositional perspective. On this respect, Verkuyl (1972) may be considered as one of the main pioneer authors who carried out compositionality studies 
on aspect. ${ }^{4}$ Following this line of thought, Aktionsart compositional analysis have been realized mostly at two different levels; Mourelatos (1978: 421) for instance, considers several factors which are involved in the overall aspectual construal such as the verb's inherent meaning, the verb's arguments, adverbials, aspect and tense. Brinton (1988) on the other hand, follows closely Vendler's proposal by contemplating some basic Aktionsart which are expressed by the predicate—state, activity, achievement—and others which are compositional.

Nevertheless, as Albertuz (1995) notices, a compositional analysis of Aktionsart is not exempt from problems. Thus, this author sustains that compositional studies do not usually stipulate the specific nature of the features involved (in the case of accomplishments for instance, it is not specified what is exactly a goal); or the fact that the interaction of features will not always produce regular results (not every activity with a goal yields an accomplishment, e.g., $\mathrm{He}$ was pushing the cart, where the progressive makes the SoA be construed as an activity).

Throughout the current research, the compositional nature of $A k$ tionsart will be studied by analyzing some relevant factors that are involved in determining the aspectual representation for a particular clause. The aim of this study will not consist of providing a definite inventory of these factors but rather of pointing how the combination of significant elements may influence on the Aktionsart interpretation.

After having stated the main characteristics of Aktionsart and introduced the issue of compositionality, in the remainder of this paper I devote my attention to the analysis of individual sentences

\footnotetext{
${ }^{4}$ This aspectual polivalency was also seen in Vendler (1967) in a twofold way; the first one is inherently attested in the fact that most of the accomplishments are constituted by an activity verb plus a referential NP, and the second one is directly acknowledged as the distinction between a dominant use (e.g., run, as an activity) and a derived use (e.g., run a mile, as an accomplishment).
} 
drawn from the British National Corpus. First of all, I consider some examples which are not so clear-cut and raise some questions as regards VV\&LP's classification. Then, other sections are dedicated to the influence of factors such as adverbials, grammatical aspect and tense on verbal predicates and how this conditions the choice of $A k$ tionsart type.

\section{Van Valin \& LaPolla's Aktionsart Typology: Doubtful Cases}

As stated above, the term Aktionsart refers to the inherent temporal characteristics of verbal predicates and as such they are classified into four basic classes: states, activities, accomplishments and achievements. As showed above, VV\&LP (1997) also distinguish four causative counterparts to the prior Aktionsart classes: causative state, causative activity, causative accomplishment and causative achievement. However, the realization of these predicates has been minimal in the examples from the BNC, which consist mainly of causative states. This can be seen in the following examples:

(5) a. A6J 1007. The effort of thinking up a new way to tackle a dragon, a beloved dragon, daunted her for a minute.

b. CBT 2404. The Treasury and the US Congress have provided $\mathrm{c}$. Clinton with some statistical support for this perception, but not for the revenue estimate.

d. BNA 2056. A little background knowledge will make you more confident and help you to draw up a list of really relevant questions.

e. FR0 3303. You could have killed me any time you wanted to $(\ldots)$. 
The three sentences in (5a), (5b) and (5c) illustrate causative states, while $(5 \mathrm{~d})$ constitutes a causative achievement. ${ }^{5}$ Following VV\&LP (1997), in order that the previous sentences express induced SoAs, they can be paraphrased into their causative form always keeping the same number of core arguments. Therefore, the sentences in (5) could be paraphrased in the following way:

(6) a. The effort of (...) caused her to be daunted for a minute.

b. The Treasury and the US Congress have caused Clinton to have some statistical support (...).

c. A little background knowledge will cause you to be more confident (...).

d. You could have caused me to die any time you wanted to.

Nonetheless, I do not deem it necessary to maintain the existence of causative predicates as another class of Aktionsart. Thus, as illustrated by (5) causative relations can be present in several SoAs, but I do not think this is a property encoded just in the verbal predicate, but rather a property of the whole predication itself. This claim could seem controversial since the same may be asserted about the four basic Aktionsart types: verbs may have a different Aktionsart interpretation in the context of a particular sentence from what we may determine to be its basic or lexical Aktionsart interpretation (VV\&LP 1997: 99); however, even if the choice of Aktionsart depends most of the times on other sentential constituents than the verb, we can still talk about a basic or prototypical Aktionsart interpretation for each predicate (i.e., melt: accomplishment; explode: achievement; walk: activity; believe: state). This fact, per contra, cannot be applied to particular verbs as having a prototypical causa-

\footnotetext{
${ }^{5}$ VV\&LP (1997: 112) consider a verb like kill as a causative accomplishment. However, I would rather view it as a causative achievement since both kill and die denote punctual events.
} 
tive meaning as can be seen in the own VV\&LP's examples (1997: 97):

(7) a. Achievement

b. Causative achievement

c. Accomplishment

d. Causative accomplishment
The balloon popped.

The cat popped the balloon.

The ice melted.

The hot water melted the ice.

Both in (7a) and (7a') we find the realization of the same verb, pop, which is usually interpreted as an achievement Aktionsart predicate. Similarly, we have melt in $(7 \mathrm{~b})$ and $(7 \mathrm{~b}$ '), in this case a prototypical accomplishment predicate. Although we are dealing with the same predicates, VV\&LP (1997) assign a different Aktionsart interpretation to (7a') and (7b'), that is, causative achievement and causative accomplishment, respectively. This would not be a problem, since, as stated above, the same verb can have different Aktionsart interpretations in different contexts. Nevertheless, VV\&LP's (1997) Aktionsart choice in (7a') and (7b') is attributed as a property encoded in the verb, and we can see that the causative relation emerges not because of the predicate but because of other sentential constituents (in this case the relation between two arguments, agent an patient). Therefore, instead of dealing with causative predicates I would consider (7a') and (7b') as an achievement and an accomplishment, respectively, in which a causative relation holds.

As we saw above, apart from the four basic Aktionsart classes and their corresponding causatives, VV\&LP (1997) consider a fifth type of predicate which they term active accomplishment, i.e., the accomplishment use of activity verbs. The examples in (8) illustrate these kinds of predicates:

(8) a. APW 635. Lachlan walked slowly up to his room and stared down at his wife lying smiling at him.

b. HH9 1699. Then she drank a glass of water and felt it 
trickle slowly down inside her as if she were a pipe.

c. ADO 1357 So you would need to eat between eighteen and thirty cakes to add $2 \mathrm{lb}(1 \mathrm{~kg})$ of fat in a day.

All the predicates in (8) are prototypical activities, which due to the specification of a definite object-(8a) to his room, (8b) a glass of water and (8d) between eighteen and thirty cakes-behave like accomplishments, and consequently are denominated active accomplishments. As it was the case with causative verbs, I do not find enough solid evidence for making active accomplishments part of an Aktionsart typology. Accordingly, a predicate should not be represented in the lexicon as an active accomplishment since this is obviously an effect of the linguistic context. Even VV\&LP (1997: 112) remark that it is necessary to distinguish the basic lexical meaning of a verb, e.g., eat as an activity verb, from its meaning in a particular context, e.g., eat a slice of pizza as an active accomplishment predication. Then, when we talk about active accomplishments we are dealing with the occurrence of a predicate in a specific clause, therefore this category should not be regarded as an Aktionsart type, given the fact that Aktionsart refers only to properties of linguistic predicates, not to properties of states of affairs (VV\&LP 1997: 92). Let us also consider the following examples:

(9) a. She knocked at the door.

b. She was knocking at the door.

c. Mary closed the door very slowly.

d. Mary closed the door with a slam.

Sentence (9a) depicts an achievement and sentence (9c) an accomplishment; the addition of the progressive in (9b) brings dynamicity to the SoA, resulting therefore in an activity. As regards (9d), the adverb with a slam presents the SoA as occurring instantaneously, hence it would be considered as an achievement. Following 
VV\&LP (1997) reasoning, perhaps we should term (9b) something like 'active achievement' or (9d) like 'accomplished achievement'. However, this cannot be an appropriate solution since the task of classifying predicates into Aktionsart types would become too complex. Thus, in (9a) and (9b), we have again verbs which prototypically behave as an achievement 'knock' and as an accomplishment 'close', and their interpretation as activity and achievement, respectively, depends on the influence of the linguistic context in a particular clause. Thus, the lexical entry a predicate may have in terms of an Aktionsart typology and its construal in a given utterance should not be confused. Accordingly, the class active accomplishment cannot be regarded as another type of Aktionsart since it deals with predicate realizations in specific sentences. Therefore, I will consider examples like those in (8) as plain accomplishments. Following the arguments for causatives above, the category of causative active accomplishment will not be considered.

As an outcome of my previous analysis I will just consider the four basic Aktionsart classes ${ }^{6}$ - states, activities, accomplishments, achievements - throughout the remainder of this paper, discarding active accomplishments and causatives as Aktionsart types. Nevertheless, as it will be shown below, even this classification may present several doubts when ascertaining the type of predicate.

\section{Telicity}

In this section I focus my attention on how the telicity of a predicate can be determined and/or influenced by other clausal constituents. Of special relevance are the adpositions considered by VV\&LP

\footnotetext{
${ }^{6}$ The four basic Aktionsart classes will deal with prototypical predicates; as regards the Aktionsart interpretation of a whole clause it will be seen that other kinds of situations will emerge.
} 
(1997: 95), for and in. These authors remark that PPs introduced by for usually take place with activities, since they expresses durationand occasionally with accomplishments and states; whereas PPs introduced by in, often occur with accomplishments and achievements ${ }^{7}$ due to the fact that they indicate completion. This can be seen in the following examples from the corpus:

(10) a. ALP 485. (...) he was unable to complete a crossword puzzle in ten minutes as he once could troubled him.

b. A08 244 (...) I am under no illusion that the big glass will in an instant blow all that away (...).

c. H9U 686. For an hour or two he worked very well.

d. AC4 2324. For a minute the icy eyes were distant, remembering something pleasurable.

In (10a) the predicate complete constitutes an accomplishment, that is, it depicts a SoA with an inherent terminal point as evidenced by the PP in ten minutes, which denotes the beginning and the end of the process. In (10b) on the other hand, the predicate blow away is [+punctual] given the fact that the PP in an instant expresses a very short period of time. The verb worked in (10c) represents an activity with the PP for an hour or two expressing its duration but not its terminal point, that is, the action could go on at a later time. Finally, the copula were in (10d) embodies a state with a short duration.

As regards in-PPs, and as VV\&LP (1997: 96) point out, we may find many examples where they take place with activities and achievements; in most of these cases however, the adposition in does not express duration, but it makes reference to the time passing until the beginning of the SoA. This is exemplified by (11):

\footnotetext{
${ }^{7}$ If they express a very short period of time such as 'in a second', 'in an instant'... etc.
} 
(11) a. B04 1214. Pigs often lie down and chew on nothing; they may consume their food in ten minutes during the day.

b. HYV 320. (...) we're gonna be moving on in a minute.

c. FRK 268. He'll kick that door down in ten minutes.

In (11a), the PP in ten minutes designates the duration of the whole process of consuming food (hence an accomplishment). However, the PP in a minute in (11b) does not refer to the duration of the SoA, but to the time that will pass until the onset of the action to move on. The example in (11c) is more ambiguous. In this case, two different interpretations may be given to the $\mathrm{PP}$ in ten minutes; the first one is the durational interpretation, that is, the process of kicking a door may take the agent ten minutes, which would yield an accomplishment. Thus, we could imagine a situation where the agent is kicking repeatedly a door until he finally breaks it down. In this sense, the act of kicking could be interpreted as an iterated achievement, hence an activity, but the particle down implies an inherent goal other than kicking, that is, kicking down the door, which would constitute an accomplishment. ${ }^{8}$ Nevertheless, we can also construe in ten minutes as referring to the time that will pass by until the subject will kick that door; in this case then, kicking a door could be conceived as a punctual event and therefore as an achievement.

With reference to the contextual effect of in and for PPs on $A k$ tionsart, let us consider the following examples:

(12) a. Peter sang for an hour.

b. Peter sang in an hour.

c. Mary painted the wall in 30 minutes.

\footnotetext{
${ }^{8}$ An interesting study concerning these kinds of post-verbal particles is Brinton's (1988). Thus, the author (1988: 163) ascribes an aspectual (telic) meaning to particles such as up, down, off, over, out, etc. since they denote the goal or endpoint of a situation.
} 
d. Mary painted the wall for 30 minutes.

In (12a) the predicate sang represents an activity which had a temporal duration of an hour; nevertheless, it does not have a terminal point since the action of singing could continue afterwards. In (12b), on the other hand, we see that by changing the adposition of for into in, the act of singing is construed now as having a beginning and an end, that is to say, it is likely that Peter had a fixed repertoire of songs which he sang in an hour; consequently the predicate in (12b) would be an accomplishment. In a similar fashion, painted in (12c) constitutes an accomplishment in which the process of painting a wall took 30 minutes. On the other hand, the PP for 30 minutes in (12d) does not imply that Mary did finish painting the wall, it just asserts that an action went on for a certain amount of time but it does not settle its beginning or end. Accordingly, the examples in (12) show that the same predicate may have different Aktionsart interpretations depending on whether we have an in-PP or a for-PP.

On this issue, Albertuz (1995: 326) points out that los CCIRs ${ }^{9}$ durativos no prueban el carácter del proceso respecto del parámetro de la telicidad sino que, cuando se añaden a una cláusula, son los responsables del mismo. As regards the previous statement, it should be noted that I agree with part of it. Thus, and as evidenced by the examples in (12), I consider that the occurrence of for-PPs with telic predicates (accomplishments) will make the SoA be atelic whereas the realization of temporal in-PPs will yield a telic SoA. This fact would contradict some of VV\&LP's (1997: 96) examples such as The clothes dried for ten minutes where the for-PP is regarded as expressing the temporal duration of a telic process; however, similarly to (12d), the for-PP in the previous example im-

\footnotetext{
9 Albertuz (1995: 324) refers with this abbreviation to 'complementos circunstanciales' of the kind English: for, French: pendant, Spanish: durante, etc. and English: in, French: en, Spanish: en, etc.
} 
plies that the clothes were drying for that amount of time, but it does not convey that the clothes finally got dried.

Nevertheless, I do not agree with Albertuz's claim about considering durational PPs as the only responsible factor for the telicity of a SoA. As it will be shown below there are several other elements implied in the attainment of a terminal point.

In this sense, another constituent which plays an important role with respect to telicity is what VV\&LP (1997: 122) refer to as the second argument of activity predicates. This argument must be nonreferential (usually a mass noun or a bare plural) so that the predicate is construed as an activity; in this case the argument is termed 'inherent argument' since it expresses an intrinsic facet of the meaning of the verb and does not refer specifically to any participants in an event denoted by the verb (VV\&LP 1997: 123). This argument also has specific properties: it can be omitted (e.g., She was drinking), and it can be incorporated into the verb (e.g., beer drinking). However, when we find the realization of an argument which refers to a specific referent, then the predicate is interpreted as an active accomplishment. ${ }^{10}$ This is illustrated in the examples in (13):

(13) a. ANF 1382. Louis Libaude and William Kundig also purchased paintings and finally a banker (...) bought six portraits.

b. CH8 2383. Once a guy came running (...), he must have run fifty yards up the road (...).

The first two sentences in (13) clearly illustrate the alternation between activity and accomplishment in terms of the referentiality of a second argument. In (13a) the predicate purchase has as a second argument a bare plural and therefore non-referential NP, paint-

\footnotetext{
${ }^{10}$ Following the reasoning in a previous section, instead of active accomplishments I will deal with accomplishments.
} 
ings, hence the SoA constitutes an activity. In a similar way, bought's second argument is a plural NP, but in this case a referential one as determined by the numeral six; thus, this specific amount provides a delimitation of the event and the terminal point is attained when the six portraits have been bought. Accordingly, the predicate bought in (13a) represents a telic process, that is to say, an accomplishment. In (13b) we find a similar example but in this case with the same predicate; while in the first case the verb run represents an activity, in its second realization it co-occurs with a referential NP, fifty yards, resulting therefore in an accomplishment.

As evidenced by the previous sentences, most of the accomplishment examples in the corpus are accompanied by a definite NP. Nevertheless, the existence of a referential second argument does not mean that the predicate is necessarily interpreted as telic. Let us consider the examples in (14):

(14) a. AD9 3500. Ari was shaking her head more vigorously, although her face had crumpled.

b. Tom read the novel for two hours.

c. HGS 1906. If you kick your child all his schooldays, force him to labour sixteen hours a day seven days a week, (...), then you have educated a man, in the best way possible, to be indifferent.

In (14a) the predicate shaking has a referential NP, her head; this case however, constitutes an activity due to two factors: the progressive $^{11}$ and the presence of the adverb vigorously, which provide dinamicity to the SoA. Anyway, the interpretation given to this example might be an iterative one since to shake is inherently a telic

${ }^{11}$ According to VV\&LP (1997: 94) the progressive can also appear with accomplishments (The ice was melting). However, I think the influence of the progressive on inherent telic predicates may bring some consequences as regards the Aktionsart choice. This will be dealt with in section 5 . 
predicate. The example in (14b) is similar to (12d) presented above; the predicate read occurs with the definite NP the novel, but the PP for two hours provides in this case a non telic interpretation to the verb. Thus, the meaning conveyed by (14b) is that Tom was reading a novel during a period of two hours but he did not necessarily finish reading that novel. In (14d) the inherent telic predicate kick appears with the referential NP your child; in this case, the adjunct all his schooldays indicates a temporal duration similar to the one introduced by for. This provides the predicate with a sense of habituality and continuity-thereupon an activity, which should be construed iteratively.

So far, I have only dealt with the effect of object NPs on Aktionsart since the main concern in this section was telicity. However, a few remarks should be done about subject NPs and their influence to the different types of SoAs. Thus, let us consider the ensuing sentences:

(15) a. A bomb exploded yesterday in Bogotá.

b. Bombs exploded yesterday in Bogotá.

The previous examples show that the countability or referentiality of the subject may also have effects on the Aktionsart interpretation. In this sense, it seems that with punctual predicates, an achievement reading is only possible with singular count arguments (15a) or definite plural NPs. However, if this argument is nonreferential (15b), we get an achievement construal in an iterated way, hence an activity.

With respect to the effect of NPs on Aktionsart, Brinton (1988: 50) provides the following table: 
Table 1. The effect of NP arguments on Aktionsart

\begin{tabular}{|c|l|}
\hline $\begin{array}{l}\text { 1. Activity (or accomplishment) } \\
\text { verb + singular or specified plu- } \\
\text { ral count argument }\end{array}$ & $\begin{array}{l}\text { Accomplishment } \\
\text { She sang the song, The child ate the } \\
\text { pieces of candy }\end{array}$ \\
\hline $\begin{array}{l}\text { 2. Activity (or accomplishment) } \\
\text { verb + mass or unspecified plu- } \\
\text { ral argument }\end{array}$ & $\begin{array}{l}\text { Activity } \\
\text { She sang songs, The child ate pieces } \\
\text { of candy }\end{array}$ \\
\hline $\begin{array}{l}\text { 3. Achievement verb + singular } \\
\text { count argument }\end{array}$ & $\begin{array}{l}\text { Achievement } \\
\text { He noticed an error in the paper, } \\
\text { The runner crossed the finish lane }\end{array}$ \\
\hline $\begin{array}{l}\text { 4. Achievement verb + specified } \\
\text { plural argument }\end{array}$ & $\begin{array}{l}\text { Accomplishment } \\
\text { He noticed six errors in the paper, } \\
\text { The first three runners crossed the } \\
\text { finish lane }\end{array}$ \\
\hline $\begin{array}{l}\text { 5. Achievement verb }+ \text { unspeci- } \\
\text { fied plural argument }\end{array}$ & $\begin{array}{l}\text { Activity } \\
\text { He noticed errors in the paper, Run- } \\
\text { ners crossed the finish lane }\end{array}$ \\
\hline $\begin{array}{l}\text { 6. State verb + singular or plural } \\
\text { count or mass argument }\end{array}$ & $\begin{array}{l}\text { State } \\
\text { Mary owns a car/ two cars/ cars } \\
\text { Mary has money }\end{array}$ \\
\hline
\end{tabular}

Brinton (1988), in my belief, expresses significant occurrence patterns in the previous table. Nevertheless, the author does not specify that the previous patterns may be also affected by other factors such as adverbials or certain kinds of operators, which can lead to a different Aktionsart interpretation (e.g., She was singing the song, where the effect of the progressive implies that the endpoint might have not been reached). Furthermore, I do not agree on the accomplishment reading given to sentences such as He noticed six errors in the paper and The first three runners crossed the finish lane. These cases in my opinion, represent achievements given the fact that each one denotes a telic and punctual event; that is, noticed for instance expresses a bounded situation given the referentiality of the argument six errors, where each error 'notice' constitutes an instantaneous event. It could be reasoned that this analysis could be in 
a way applied to the sentence above Bombs exploded yesterday in Bogotá, since each bomb explosion is also a telic SoA; however, this case was considered an activity since it represents an unbounded situation given the non-referentiality of bombs.

Summarizing, as far as telicity is concerned, it has been shown that it is a complex feature that cannot be determined just in terms of PPs, referential NPs or the predicates themselves. In the following section I deal with other clausal elements, in this case operators, which also have a significant role concerning telicity and Aktionsart choice in general.

\section{Viewpoint Aspect and Aktionsart}

As regards the influence of aspectual operators on situation aspect, it will be seen that probably the most significant one in terms of altering an Aktionsart interpretation is the progressive. However, some comments should be done first concerning the effect of perfective and imperfective aspect. Let us have a look at the following examples:

(16) a. Rose is eating her lunch.

b. Rose eats her lunch everyday at noon.

c. Rose ate her lunch.

d. She is swimming in the river.

e. She swims in the river every summer.

f. She swam in the river.

g. I was in Brazil last July.

As evidenced by (16a) and (16b), the effect of imperfective aspect on telic predicates 'withholds' in a way the attainment of their inherent goal. Thus, in (16a) the fact that Rose is eating her lunch does not necessarily mean that Rose did finish eating her lunch. The 
influence of the habitual aspect on telic and dynamic SoAs is somehow different; thus, both SoAs in (16b) and (16e) are viewed imperfectively ('incomplete') in the sense that each one denotes a situation which is characteristic of an extended period of time, that is, the situation is regarded not as a contingent property of the moment but, precisely, as a characteristic feature of a whole period. In this way, although (16b) for instance, implies that the goal of Rose's eating her lunch is reached on every single occasion, I think an accomplishment reading would not capture explicitly the connotations provided by the habitual aspect (i.e., that the process is repeated over and over). I will leave this question open for now, which will be taken up again below in my discussion on temporal operators and Aktionsart.

As regards the occurrence of the perfective aspect with a telic situation (16c), it can be seen that although the notion of goal is part of the lexical aspect, the grammatical aspect (perfective) supplies a sense of completion or of goal having been reached. Imperfective aspect for an atelic SoA, (16d) and (16e), denotes the existence of a situation highlighting its durative or incomplete status. Per contra, the perfective of an atelic situation (16f) asserts the existence of a SoA, including its beginning and cessation at some definite point in time. In other words, although the SoA has not attained any goal, it is viewed as complete due to the influence of the perfective. Finally, $(16 \mathrm{~g})$ constitutes a state in the perfective aspect. On this issue, it was claimed somewhere else that states are characterized by the inherent qualities of duration and homogeneity, as well as by the lack of limits. However, by expressing a state in the perfective we are placing boundaries on the situation referred to, that is, we see the SoA as a 'whole'. In this sense, several authors such as Michaelis (1998: 23) argue that cessation is a form of dynamism, insofar as it entails change from one phase (existence of the state) to another (lack of that state), and hence they interpret the examples such as (16g) as activities. Nonetheless, in my opinion, the predicate lie in The cup 
lied on the table for one minute for instance, makes reference to a static situation during the period of one minute; that is to say, during that time the verb lie cannot be attributed any dynamicity, it is just describing the location of a participant during a determinate period of time. Therefore, I would consider inappropriate to regard the situation in (16g) as an activity, since it does not code a happening or a dynamic SoA where an agent does something. This has to do with the fact that most states, if not all, have a beginning and an end.

Let us focus now on the progressive aspect. In this sense, VV\&LP (1997: 94) put forward that the progressive is an indicator of the features [-static, -punctual], and that it only occurs with activities and accomplishments. The progressive presents the situation in progress, as continuous and incomplete, hence its incompatibility with punctual and stative predicates. As regards stativity, VV\&LP (1997: 655) point out that several state predicates may take the progressive, such as sit, stand and lie, and when they do so, they refer to situations that are not necessarily permanent (e.g., The dog is sitting on the grass). However, as illustrated by (17), the occurrence of the progressive with prototypical state predicates is quite common:
(17) a. She is not being herself.
b. Ana is feeling better.
c. I'm thinking about the final exam.

The previous examples illustrate state predicates in the progressive aspect. In this sense, Goosens (1994: 168) remarks that the addition of the progressive to a prototypically non-dynamic SoA makes it acquire a dynamic interpretation. Thus, Goosens (1994), together with other authors such as Smith (1983) or Michaelis (1998), advocates an activity reading for cases such as those in (17). On the other hand, several other authors like Lyons (1977) or Comrie (1995), point out that the influence of the progressive provides the stative SoA with temporariness instead of being contem- 
plated as permanent and essential. However, I think that for an adequate and satisfactory account of the effect of the progressive on stative situations a 'middle' point should be attained between the previous extreme positions. In this way, I will differentiate between states in the progressive with an activity construal and states in the progressive with a temporary interpretation. As far as the former class is considered, Leech's (1998) account on the use of the progressive constitutes a significant guideline. Thus, this author (1998) attributes a different meaning to certain kind of predicates depending on their occurrence with the progressive form. Thus, Leech (1998: 24) talks about the three kinds of verbs.

The first kind of verbs refers to the verbs of inert perception: e.g., feel, hear, see, smell. These verbs appear generally in the nonprogressive form whenever the perceiver is merely a passive receptive: e.g., I felt something under my sweater, I can smell the flowers. However, they usually take the progressive aspect when they indicate 'active perception': e.g., I'm feeling the ground with my foot, I'm smelling the perfume. As Leech (1998: 27) points out in these cases the speaker focuses his attention on some object whereas in passive perception the sensation simply happens to the speaker. The author also remarks that with the predicates see and hear the progressive aspect cannot take place even in cases of active perception:

(18) Passive perception

I (can) see a bird

I (can) hear a strange sound
Active perception

I'm looking at a bird

I'm listening to a strange sound

Nevertheless, some examples from the BNC show the occurrence of see and hear in the progressive:

(19) a. H8M 2191. I can't believe what I am seeing.

b. G10 1722. I am hearing the echoes again, thought Grainne, staring about her, her eyes huge and dilated. 
70 Towards a Universal Typology of State of Affairs

c. K95 2018. 'Sir John', he rasped, 'I am hearing this man's confession!'

The first two sentences, although the predicate is in the progressive, refer in my belief, to passive perception, hence they constitute states. Thus, the use of the progressive would emphasize the ongoingness of a current situation and its probable temporariness. On the other hand, (19c) would rather express active perception, since the agent is clearly involved in the action, that is, he is 'listening' to a man's confession.

The second type of verbs are the verbs of inert cognition: e.g., believe, hope, think, know, consider. Again, these predicates are usually expressed in the simple form (non-progressive) when there is a lack of dynamicity: e.g., I think the gossip isn't true, I hope you can come to the party, I know three different kinds of languages. Nevertheless, when the previous verbs denote some active mental activity it is quite common to find them in the progressive: e.g. I'm considering their proposition, I'm thinking of you.

The third refers to state verbs of having and being: e.g., be, belong to, contain, cost, have. Once more it is usual to find these types of verbs in the simple form: e.g., I have a beautiful house by the beach, This bike belongs to Pablo, Apples cost a lot. However, some of these predicates can also be construed in a non-static way: She is not being herself. In this verbal 'category', I would also point out that it is quite relevant the fact that a SoA refers to a permanent property of an entity; ${ }^{12}$ cases like these will be always expressed in the simple form: e.g., He has blue eyes, I'm Spanish.

Thus, concerning the examples above, I would consider the situations expressed in the simple form as states, since they repre-

\footnotetext{
12 This distinction is relevant for instance for the choice of the copula in Spanish ser vs. estar, which serves to denote inherent properties from 'temporary' states: e.g., Soy española vs. Estoy contenta.
} 
sent static and homogeneous SoAs. However, sentences like I'm smelling the perfume, I'm thinking about what you said, I'm considering their proposition or She is not being herself should rather be interpreted as activities because they constitute dynamic SoAs where the agent is actively involved in performing an action, that is, they are agentive situations. Thus, She is not being herself for instance, expresses a kind of behaviour over which the person has control, rather than as an inherent trait of this person's character. With respect to examples like the ones above, Michaelis (1998) proposes a different kind of analysis. Thus, this author (1998: 41) postulates that a sentence like $I$ see the mountains is regarded as a state since the stimulus is non-transitory (the mountains); however, in a sentence like I saw a flash, where the stimulus is ephemeral, Michaelis (1998) posits that the predicate is viewed as non-static. The author argues that this is also evidenced by the fact that the previous SoA cannot be denoted by the present tense. However, I would rather discard this analysis since the main difference between both sentences is that while in the first case the situation is expressed imperfectively, in the second case ( I saw a flash) the SoA is viewed in a perfective way, that is, as a 'complete' SoA. Besides, the use of the present tense in the latter case is laid aside since generally it provides a situation with continuity, and a flash constitutes a very short duration entity. Thus, although I saw a flash denotes a brief temporal situation, it lacks any dynamicity (being the speaker a passive receiver of a particular sort of stimulus) and therefore represents a state.

Nonetheless, the previous claim about the occurrence of the progressive with states does not imply that all the states should be construed as activities; let us consider the following examples:

(20) a. Mary is looking too pale today.

b. Robert is lying on the grass.

c. I'm feeling a bit sick. 
As illustrated by (20), although the predicates appear in the progressive, the SoAs are not construed as dynamic situations where the participants are involved in a certain kind of action. Thus, in these cases the effect of the progressive aspect is to present the SoAs as temporary in contrast with their respective variants in the simple form: Mary looks too pale today, Robert lies on the grass, I feel a bit sick. Accordingly, I deem it necessary to make a further distinction among stative predicates (or even better, between stative SoAs); in this way a pure stative class exemplified by examples like Juan is happy can be differentiated from another class which represents transitory states like Mary is looking pale. Consequently, I will term cases like the latter ones as 'episodic states'. On this respect, it could be argued that a state like Juan is happy also denotes an ephemeral SoA. Indeed, the situation of Juan being happy can be even shorter than the situation of Mary looking pale for instance. However, in the first case, we usually conceptualize the state of happiness as one intrinsically unbounded, while in the latter case, the state of looking ill is regarded as inherently unstable.

Consequently, the fact of ascribing an activity construal or a temporary reading to a prototypical stative situation in the progressive will usually depend on several factors such as the involvement of dynamicity/agency, limited duration and once more, our knowledge of the world.

As regards the occurrence of the progressive with momentaneous situations, both Dowty (1977) and Langacker (1991) remark their incompatibility, since it is difficult to construe an achievement as having any internal structure due to its supposed punctuality. However let us have a look at the sentences in (21):

(21) a. Sam was knocking on the door.

b. Hundreds of balloons were popping in New Year's Eve.

c. He is winning the race.

d. They are reaching the summit! 
e. She was beginning to sing when you came.

With respect to the examples (21a) and (21b), we find two achievements predicates, knock and pop in the progressive; in both cases, the Aktionsart interpretation would be an activity construed in an reiterated way, given the fact that both knock and pop are inherently telic predicates. In this sense, although an activity interpretation would express the dynamicity and durative character of the previous sentences, I think it should be more convenient the use of a different 'label' which captures the fact that we are dealing with a repetitive set of punctual events. Thus, I would propose to term cases like (21a) and (21b) as 'durative achievements'. However, not all the punctual predicates in the progressive have to be interpreted iteratively. This can be seen in (21c), an example taken from Mourelatos (1978). According to this author, the achievement predicate in this case, though it appears in the progressive, does not have an iterative interpretation; that is, the SoA He is winning the race refers to the process directed towards the winning, and in this way the situation is regarded as having an extended internal structure.

Similarly, the punctual predicates reach and begin have a durative interpretation in both (21d) and (21e) but not in a reiterated way. Nonetheless, under the influence of the progressive, these three predicates cannot be regarded as [+punctual] nor even as [+telic] any more. Below it will be suggested a different term for these kinds of SoAs.

With respect to telicity, if the progressive is added to a bounded predicate, it tends to mean that an action was working towards completion, but was as yet incomplete (VV\&LP 1997: 94). Nevertheless, these authors remark that not being telic is not a function of the progressive since we may find examples like The snow was melting, where the accomplishment verb melt indicates that there is a terminal point at which the snow will be melt.

However, let us consider the following examples where we find 


\section{Towards a Universal Typology of State of Affairs}

prototypical accomplishment predicates:

(22) a. Harry had recovered from his illness when it started to rain.

b. Harry was recovering from his illness when it started to rain.

c. Tom built that house yesterday.

d. Tom was building that house yesterday.

In (22a) and (22c) the predicates represent accomplishments, that is, they all denote bounded processes and co-occur with referential NPs that also indicates their telicity. However, in the progressive version of the previous sentences, $(22 b)$ and $(22 d)$ the SoAs are atelic. To this, it might be objected that the progressive variants also have an in-built terminal point. However, even though we have the same referential NPs, the effect of the progressive presents the SoA as something incomplete; that is, Harry in (22a) had actually recovered from his illness, but the context may imply that he was going to get sick again. However, the same cannot be claimed of (22b); thus, it is implied that Harry did not reach the goal of recovering from his illness and the context presupposes that, due to the rain, the recovery would be postponed. Similarly, if in (22c) it is true that at a particular point of the process Tom was building that house, we cannot say on the other hand that Tom did build that house as regards (22d). That is, an outcome may or may not be attained at a later stage. Therefore, with the use of the progressive the speaker's attention is focused on the action but not on the action plus goal. Thereupon, this fact would constitute an evidence against VV\&LP's claim that the progressive does not influence the telicity of a predicate. On this topic, Bache (1997: 241) differentiates in his classification between atelic and non-static SoAs-activities-from telic predicates (accomplishments) in the progressive aspect like the examples in (22). In the former case, this author denominates these SoAs as selfcontained situations, that is, atelic situations with no terminal point 
-activities in VV\&LP's terms; whereas in the latter case, Bache (1997) talks about directed situations, atelic situations advancing towards, but not including, a terminal point. For the sake of familiarity, I will rather keep the term activity for referring to atelic and dynamic SoAs instead of self-contained situations; however, and following Bache, I consider adequate the use of a different term for situations directed towards a goal (but not including it). Thus, I will keep Bache's terminology but differentiating whether it deals with achievements like those in (21c), (21d) and (21e)-directed achievements-or it deals with accomplishments like those in (22) in the progressive-directed accomplishments (thus, the example above commented by VV\&LP The snow was melting represents a directed accomplishment).

From the previous examples, it can be concluded that the progressive has significant effects on Aktionsart classes. Following Albertuz (1995: 332) el progresivo añade a los verbos las propiedades de los que éstos inherentemente carecen. A los verbos puntuales los dota de duración; a los estativos les otorga transitoriedad. And on this issue, I would also add that the progressive also tends to entail non-telicity to telic predicates. Consequently, predicates cannot be classified into Aktionsart types following the progressive test put forward by VV\&LP (1997). That is, almost any verb can occur in the progressive, and therefore, we are dealing once more with particular realizations of predicates in specific clauses. Thus, the features of punctuality, stativity and telicity are usually predicted from occurrences of clausal constituents in an explicit linguistic context.

About the relationship between Aktionsart and temporal operators, the interaction of the present tense with the different Aktionsart classes can be highlighted. Let us consider the following examples:

(23) a. Water boils at $100 \mathrm{C}^{\mathrm{o}}$.

b. Cows eat grass. 
c. I go to the beach every year.

d. Mary walks every day in the park.

Examples (23a) and (23b) represent 'eternal truths' or state permanent conditions in our projected world. On the other hand, the predicates in (23c) and (23d) depict general habits as evidenced by the adjuncts every year and every day, respectively. The previous situations are usually expressed in the present tense-or habitual aspect as shown above; habitual aspect in this sense describes a situation which is typical of an extended period of time, that is, the situation does not take place at a specific moment, but it occurs repeatedly throughout the whole period of time referred to. It should be remarked that habituality denotes imperfective meaning since the focus is not placed on the beginning or end of a situation, but on its reiterated occurrence. As regards the influence on the Aktionsart choice it could be claimed that the SoAs in (23) are static since in fact, they do not report any specific happenings. Nonetheless, I do not think that 'state' is a suitable categorization either, since each occurrence of the previous situations constitutes a dynamic event per se (e.g., I go to the beach every year-accomplishment). Accordingly, I propose to use the label 'constant' ${ }^{13}$ plus the Aktionsart type involved in the utterance; thus (23a) would constitute a constant achievement, (23b) a constant activity, (23c) a constant accomplishment and finally, (23d) would represent a constant activity. Following this reasoning, I will consider the sentences in (16b) Rose eats her lunch everyday at noon and (16e) She swims in the river every summer as constant accomplishment and constant activity respectively.

Michaelis (1998: 21) also alludes to the relation between tense and Aktionsart by remarking that non-static situations, on reporting

\footnotetext{
${ }^{13}$ I think the term 'constant' is more appropriate than 'habitual' since we are also dealing with cases where eternal conditions, but not habituality, are involved.
} 
incidents ongoing at present, are incompatible with present tense and must appear in the progressive (e.g., *He falls would be odd if interpreted about a report of the present state of things). However, we may find several exceptions, like the ones illustrated in (24):

(24) a. Patrick says the situation will improve very soon.

b. I put the eggs, the flour and the sugar in a bowl; I mix them well...

c. Raúl passes to Hierro, Hierro to Ronaldo, Ronaldo shoots and scores!!

d. As soon as Stefan leaves the room, Nicolai drops a glass on the floor to attract attention.

In the previous cases the present tense is compatible with telic and punctual predicates without providing any stativity to them; thus, in (24a) say represents an atelic and dynamic SoAs (an activity); in (24b), put and mix constitute accomplishments, since they are both non punctual an telic-as evidenced also by the referential NPs the eggs, the flour, the sugar and them; the verb pass in (24c) embodies an accomplishment-it has a specific goal, to Hierro-and shoot and score are both achievements since they denote instantaneous SoAs; and finally, in (24d) - an example taken from Bache (1997: 248) leave represents an accomplishment and drop an achievement. The function of the present tense in the previous examples is not to express general habits or permanent states. In (24a) the predicate say refers to a past event; in (24d) on the other hand, the present tense is used as a more dramatic narrative expression than the past tense (usually referred to as historic present). The sentences in (24b) and (24c) on the other hand, serve as commentaries, i.e., they convey situations which are usually witnessed by the speaker and the addressee; in these cases the function of the present tense is not simply referential or propositional but rather it serves as a medium supporting or replacing a visual experience. 


\section{Conclusion and Implications for Universality}

This analysis has proved that the correlation between lexical verb and Aktionsart value is, in many cases, inaccurate. Although we find verbs which seem more closely related to some Aktionsart values than to others, such tendency is difficult, it not impossible, to describe in isolation, just on the grounds of lexical predicates, and is easily influenced by morphological, syntactic and/or contextual factors in actual discourse.

In this sense, it would be better to talk about verbs as prototypes or as having a certain Aktionsart potential which is thoroughly developed once the verb occurs in a given clause. Thus, an Aktionsart typology following the classical approach to categorization should be rejected since, as it has been proved, there are no clear boundaries concerning the 'modes of action' and they cannot be defined in terms of a set of necessary and sufficient features. The efficiency of a prototype approach is also remarked by Taylor (1995: 53): new entities and new experiences can be readily associated, perhaps as peripheral members, to a prototype category, without necessarily causing any fundamental restructuring of the category system. Thus, verbs like drop, explode, pop would be considered as prototypical achievements whereas verbs like run, walk, swim would have an atelic and dynamic potentiality, hence activities. Accordingly, I am in favour of an Aktionsart typology grounded on Vendler's classesstates, activities, accomplishments and achievements - as long as it deals with the potential values of predicates. Besides, I would also favour a typology of the most common types of situations expressed in a compositional way. The following tables illustrates this proposal: ${ }^{14}$

\footnotetext{
${ }^{14}$ I do not considered this typology as a definite and close one. Rather, I attempt to provide a classification of what are, in my opinion, the most important kinds of situations which should be distinguished when dealing with situation aspect.
} 
Table 2. Prototypical Aktionsart predicates

\begin{tabular}{|l|l|l|l|}
\hline \multicolumn{1}{|c|}{ States } & \multicolumn{1}{c|}{ Activities } & \multicolumn{1}{c|}{ Achievements } & Accomplishments \\
\hline $\begin{array}{l}\text { be, have, } \\
\text { know, be- } \\
\text { lieve, want }\end{array}$ & $\begin{array}{l}\text { run, swim, } \\
\text { walk, look, ob- } \\
\text { serve }\end{array}$ & $\begin{array}{l}\text { knock, lose, explode, } \\
\text { reach, die }\end{array}$ & $\begin{array}{l}\text { melt, eat, drink, } \\
\text { build, learn }\end{array}$ \\
\hline
\end{tabular}

Table 3. Common SoA types (influence of adverbials, NPs, etc.)

\begin{tabular}{|l|l|}
\hline \multirow{5}{*}{ States } & $\begin{array}{l}\text { - I was in Madrid last year (in the perfective) } \\
\text { - Brandon is American (inherent quality) } \\
\text { - I can see the waterfall } \\
\text { (verbs indicating passive perception) }\end{array}$ \\
\hline Activities & $\begin{array}{l}\text { - I swam in the lake yesterday } \\
\text { - She is drinking wine (non-referential noun) } \\
\text { - The snow melted for one hour } \\
\text { (prototypical accompl + durational adverbs) } \\
\text { - I'm thinking about what you said } \\
\text { (verbs indicating active perception) }\end{array}$ \\
\hline Achievements & $\begin{array}{l}\text { - They have broken the window with the stone } \\
\text { - Her grandmother died last night } \\
\text { - Then, Nicolai drops a glass on the floor } \\
\text { (historic present) }\end{array}$ \\
\hline Accomplishments & $\begin{array}{l}\text { - Jimmy has become a new man } \\
\text { - I cleaned the fish tank this morning. } \\
\text { - Rose ate in five minutes (influence of in PPs) }\end{array}$ \\
\hline
\end{tabular}

15 This case might be considered as also denoting a directed accomplishment. However, I do not think the situation is oriented towards a definite goal, but it just denotes the duration of a determinate process where the goal was not reached. 
80 Towards a Universal Typology of State of Affairs

Table 4. Other compositional SoA types (influence of the progressive and habitual/eternal truths)

\begin{tabular}{|l|l|}
\hline Episodic states & $\begin{array}{l}\text { - Ronald is sitting on the grass } \\
\text { - I'm not feeling very well }\end{array}$ \\
\hline Durative achievements & $\begin{array}{l}\text { - The cop was shooting at the thief } \\
\text { - She is knocking at the door }\end{array}$ \\
\hline Directed accomplishments & $\begin{array}{l}\text { - I'm finishing my work } \\
\text { - Fernando is playing a new song }\end{array}$ \\
\hline \multirow{2}{*}{ Directed achievements } & $\begin{array}{l}\text { - María is winning the race } \\
\text { - Scott is reaching the summit }\end{array}$ \\
\hline Constant SoAs & $\begin{array}{l}\text { - Nina always eats in the same restau- } \\
\text { rant (constant activity) } \\
\text { - Water freezes at } 0^{\circ} \mathrm{C} \\
\text { (constant achievement) }\end{array}$ \\
\hline
\end{tabular}

Accordingly it should be concluded that the different Aktionsart types discerned by authors like Vendler (1967) or VV\&LP (1997) constitute conceptual categories which do not have a straightforward linguistic codification, but which possess a number of semantically motivated grammatical factors. In this sense, the compositional character of Aktionsart is justified since actual aspectual representations may only be attributed to entire sentences. In other words, if the combination of verb and context provides an unambiguous interpretation in Aktionsart terms, class assignation should therefore, take place at this level.

Finally, it should be also remarked that although the present research has been focused on the English language, the basic typology consisting of states, activities, accomplishments and achievements, as pointed out by VV\&LP (1997), is supposed to have a universal validity across languages. ${ }^{16}$ This can be seen for instance, in the following examples taken from the Spanish, French and Basque lan-

\footnotetext{
${ }^{16}$ As regards the compositional SoAs distinguished in table 4, they would apply to languages which have a progressive aspect like English, Spanish or Icelandic.
} 
guages: ${ }^{17}$

(25) a. Basque: Estebanen ama gaur goizean hil da—achievement Esteban's mother has died this morning

b. Spanish: He comido demasiadas patatas-activity I have eaten too many potatoes

c. French: Je voudrais aller à Poitiers le dimancheaccomplishment I would like to go to Poitiers on Sunday

Likewise, the previous classification of SoAs could be also applied to an artificial language like Esperanto as it can be seen in (26):

(26) a. Esperanto estas internacia lingvo-state Esperanto is an international language

b. Mi volas lerni arton-accomplishment I want to learn art

c. Je kioma horo oni komencas labori? —achievement At what time do you start working?

d. Mi mangus iom da sodo-activity I would drink some soda

The implications of an Aktionsart typology in all the previous examples are similar to those in English. That is, predicates in (25) and (26) should be assigned a prototypical value in Aktionsart terms, but the final Aktionsart choice depends on several other contextual factors (NPs, PPs, aspectual operators, etc.) and should therefore be ascribed to the whole clause.

\footnotetext{
${ }^{17}$ Many studies as regards the expression of Aktionsart in other languages such as Russian, Italian, German, Chinese, etc., have been also carried out. See for instance Boeck (1961), Borgato (1976) or Bolsunovskaja \& Kuznetsova (1997).
} 
Consequently, and as stated above, Aktionsart cannot be regarded any more as a strictly verbal notion, but as a concept involving many other sentential constituents.

\section{References}

Albertuz, F. 1995. En Torno a la Fundamentación Lingüística. Aktionsart: Verba 22, 285-337.

Bache, C. 1997. The Study of Aspect, Tense and Action. Frankfurt am Main: Peter Lang.

Boeck, W. 1961. Wechselbeziehungen Zwischen Aspekten und Aktionen in der Russischen Sprache der Gegenwart. [Correlations between Aspects and Actions in the Contemporary Russian Language.] Wissenschaftliche Zeitschrift der Martin-Luther-Universität, Halle-Wittenburg. Gesellschafts- und Sprachwissenschaftliche Reihe 10, 225-32.

Bolsunovskaja, L. \& N. Kuznetsova. 1997. Sposoby Glagol'nogo Dejstvija v Dialektax SelÕkupskogo Jazyka. [Verbal Aktionsart in Selkup Dialects.] Linguistica Uralica 33, 202-14.

Borgato, G. 1976. Aspetto Verbale e Aktionsart in Italiano e Tedesco. [Verbal Aspect and Aktionsart in Italian and German.] Lingua e Contesto 3, 65-197.

Brinton, L. 1988. The Development of English Aspectual Systems. Aspectualizers and Post-verbal Particles. Cambridge: Cambridge University Press.

Comrie, B. 1993. Tense. Cambridge: Cambridge University Press. . 1995. Aspect. Cambridge: Cambridge University Press.

Dik, S. 1997. The Theory of Functional Gramma 2. Edited by K. Hengeveld. Berlin \& New York: Mouton de Gruyter.

Dowty, D. 1977. Toward a Semantic Analysis of Verb Aspect and the English 'Imperfective' Progressive. Linguistics and Philosophy 1, 45-77. . 1979. Word Meaning and Montague Grammar. Dordrecht: Reidel.

Goossens, L. 1994. The English Progressive Tenses and the Layered Representation of Functional Grammar. In C. Vet \& C. Vetters (eds.), Tense and Aspect in Discourse 161-177. Berlin \& New York: Mouton de Gruyter. 
Langacker, R. 1991. Foundations of Cognitive Grammar. San Diego, CA: Stanford University Press.

Leech, G. 1998. Meaning and the English Verb. London: Longman.

Lyons, J. 1977. Introduction to Theoretical Linguistics. Cambridge: Cambridge University Press.

Michaelis, L. 1998. Aspectual Grammar and Past-Time Reference. London: Routledge.

Mourelatos, A. 1978. Events, Processes, and States. Linguistics and Philosophy 2, 415-434.

Sasse, H. 1991. Aspect and Aktionsart: A Reconciliation. Belgian Journal of Linguistics 6, 31-45.

Smith, C. 1983. A Theory of Aspectual Choice. Language 59, 479-501. . 1986. A Speaker-based Approach to Aspect. Linguistics and Philosophy 9, 97-115.

Taylor, J. 1995. Linguistic Categorization: Prototypes in Linguistic Theory. Oxford: Oxford University Press.

Van Valin, R. \& R. LaPolla. 1997. Syntax: Structure, Meaning, and Function. Cambridge: Cambridge University Press.

Vendler, Z. 1967. Linguistics in Philosophy. Ithaca, NY: Cornell University Press.

Verkuyl, H. 1972. On the Compositional Nature of the Aspects. Dordrecht: Reidel. 